\title{
BMJ Open Depressive symptoms among people with HIV/AIDS in Northwest Ethiopia: comparative study
}

\author{
Tesfa Mekonen (D) , ${ }^{1}$ Habte Belete (D) , ${ }^{1}$ Wubalem Fekadu (i) ${ }^{1,2}$
}

To cite: Mekonen T, Belete $\mathrm{H}$, Fekadu W. Depressive symptoms among people with HIV/AIDS in Northwest Ethiopia: comparative study. BMJ Open 2021;11:e048931. doi:10.1136/ bmjopen-2021-048931

- Prepublication history for this paper is available online. To view these files, please visit the journal online (http://dx.doi. org/10.1136/bmjopen-2021 048931).

Received 12 January 2021 Accepted 16 June 2021
Check for updates

(C) Author(s) (or their employer(s)) 2021. Re-use permitted under CC BY-NC. No commercial re-use. See rights and permissions. Published by BMJ.

${ }^{1}$ Department of Psychiatry, Bahir Dar University, Bahir Dar, Ethiopia

${ }^{2}$ Department of Psychiatry, Addis Ababa University, Addis Ababa, Ethiopia

Correspondence to

Tesfa Mekonen;

smarthope1@gmail.com

\section{ABSTRACT}

Objectives The objective of this study was to compare depressive symptoms among people with HIV/AIDS and the general population sample. We also assessed the factors associated with depressive symptoms.

Design A comparative cross-sectional study was conducted.

Settings Antiretroviral therapy clinics in three primary healthcare facilities and semi-urban area in Northwest Ethiopia.

Participants A total of 1115 participants (558 people with HIV/AIDS and 557 comparison group) aged 18 years and above were recruited. A total of 1026 participants (530 people with HIV/AIDS and 496 comparison group) completed the interview. We excluded people with known HIV-positive status from the comparison group.

Outcome measure Patient Health Questionnaire (PHQ-9) was used to assess depressive symptoms. The proportion of depressive symptoms was compared between samples of the general population and people with HIV/AIDS using $\chi^{2}$ statistics. Multivariable logistic regression analysis was done to examine the associated factors.

Results The overall prevalence of depressive symptoms was $13.3 \%$ (11.2\%-15.4\%). The prevalence was significantly higher in people with HIV/AIDS compared with the community sample ( $16.6 \%$ vs $12.3 \%), p=0.001$. The difference was also significant in the multivariable logistic regression (OR 1.7). For the overall sample, depressive symptoms were significantly associated with older age, being single, divorced/widowed marital status, and poor social support.

Conclusions Depressive symptoms were higher in people with HIV/AIDS compared with the general population. It is necessary to include mental healthcare and screening for depression in routine HIV/AIDS care.

\section{INTRODUCTION}

HIV/AIDS continues to be a global public health threat with more than 75 million infections and 32 million AIDS-related deaths since the start of the epidemic. ${ }^{12}$ On the other hand, depression is also a major public health issue and has been considered as a global crisis because of its high contribution to the disease burden, high comorbidities with other medical conditions and associated disabilities. $^{3}{ }^{4}$ The comorbidity of depression and HIV/AIDS is common that ranged between

\section{Strengths and limitations of this study}

- Having a comparison group is one of the strengths of this study.

- Matching of variables between the study and comparison group was not employed.

- We were not able to exclude those who are HIV positive but who did not know their status in the comparison group.

- Due to the cross-sectional nature of the study, we cannot report causal relationships.

$12 \%$ and $63 \% .^{5-7}$ This was more pronounced in low resource settings, particularly in subSaharan Africa. ${ }^{89}$ A global systematic review and meta-analysis also reported that $31 \%$ of people with HIV/AIDS had depression. ${ }^{10}$ The prevalence of depression in people with HIV/AIDS has been reported as at least twice that of the general population. ${ }^{511}$ The comorbidity between depression and HIV/AIDS has significant consequences in reducing antiretroviral therapy (ART) response that leads to poor quality of life. ${ }^{12-14}$

The magnitude of depression among HIV/ AIDS patients is disproportionately high and its effect is mostly associated with poor disease progress and poor quality of life. This comorbidity is associated with multiple factors including sociodemographic, psychosocial and clinical factors. ${ }^{15-18}$ For instance, people living with HIV who received ART without HIV counselling and testing services are more likely to develop depression. ${ }^{19}$ Female gender and recent negative life events are also known contributors to depression in patients with HIV /AIDS ${ }^{20}$ However, depression remains underdiagnosed in people with HIV/AIDS. ${ }^{21}$

Depression can be prevented and treated with available resources at the primary care level. This can be achieved by early detection of depression and identifying important factors associated with depression. To prevent and manage depression in HIV/AIDS, the most important contributing factors need to 
be explored. Despite the high prevalence and negative consequences of depression among HIV-positive individuals, there is substandard care for depression in most lowincome countries' HIV care programmes. ${ }^{22-24}$

In Ethiopia, the prevalence of depression was reported $14.6 \%-48.6 \%$ among people living with HIV/AIDS ${ }^{25-27}$ and $9.1 \%$ in the general population. ${ }^{16}$ However, there was no study that compares depression in HIV-positive people and general population. It is important to see if there is any significant difference in prevalence and possible modifiable factors of depressive symptoms between HIVpositive people and the general population. Therefore, the objectives of this study were:

1. To assess the level of depressive symptoms among HIVpositive individuals in the ART clinic compared with the general population.

2. To identify factors associated with depressive symptoms in HIV-positive people and the general population.

\section{METHODS AND MATERIALS}

\section{Study design and setting}

A comparative cross-sectional study was conducted in Mecha Demographic Surveillance and Field Research Center (MDSFRC). The site is located in Mecha district, Northwest Ethiopia, which is $540 \mathrm{~km}$ away from Addis Ababa. MDSFRC is one of the newly established research centres in Bahir Dar University. We recruited people with HIV/AIDS from the adult ART clinics in the district and the comparisons from the general population.

\section{Participants}

People living with HIV/AIDS aged 18 years and above (69.8\% female) in the adult ART clinics of the district were included in the study group. For the general population comparison group, adult residents of Merawi town (a town in Mecha district) aged 18 years and above (48.4\% female) who resided for at least 6 months were included. In the comparison group, individuals with known HIVpositive status were excluded.

\section{Data collection and procedures}

Data collection was conducted through face-to-face interviews by trained data collectors in March 2018. Clinical data were retrieved from the participants' medical records. Participants were assured of confidentiality and the anonymity of the questionnaire. Supervisors and data collectors counterchecked the questionnaire every day for its completeness. Sample size was calculated using Epi Info by considering $80 \%$ power, $95 \%$ CI, $9.1 \%$ depression in the general population, ${ }^{16} 14.9 \%$ depression in HIVpositive people, ${ }^{28} 10 \%$ non-response rate, and 1:1 ratio of the study and comparative groups to detect 1.7 odds of depression in the study group. The final sample size was 1115 (558 people with HIV/AIDS and 557 comparison group).

In the community comparison group, we selected administrative villages from Merawi town by multi-stage sampling method. We randomly selected the households from the administrative villages using the registration of MDSFRC. We selected one participant using lottery method for those households with more than one eligible participant. For the study group, around 1200 individuals were estimated to attend their ART follow-up during the data collection period. We used a systematic random sampling method to select participants in every two individuals based on their appointment from the ART clinic registration logbook.

\section{Variables and measurements}

We measured depressive symptoms by Patient Health Questionnaire-9 (PHQ-9). PHQ-9 is a tool with nine items and validated in the Ethiopian population with good psychometric properties (86\% sensitivity and $67 \%$ specificity at cut-off point 10$).{ }^{29}$ Severity of depressive symptoms were also described based on PHQ-9 score $(0-4=$ no depressive symptoms, 5-9=mild depressive symptoms, 10-14=moderate depressive symptoms, 15-19=moderately severe symptoms, 20+=severe depressive symptoms) ${ }^{30}$ The tool also had good reliability in the current study (Cronbach's alpha=0.79). We have used PHQ-9 at cut-off score of 10 to identify depressive symptoms that require clinical intervention (moderate to severe depressive symptoms).

The independent variables were:

- Sociodemographic variables: sex, age, marital status, educational status and perceived relative income.

- Psychosocial variables: social support, problematic alcohol use and khat chewing

- HIV-related variables: CD4 level, duration of HIVpositive status and ART use, ART regimen, and presence of opportunistic infections

Social support was assessed using Oslo Social Support Scale (OSSS-3), a three-item scale which has a sum score that ranges from 3 to 14 (poor social support $=3-8$, intermediate social support $=9-11$, strong social support $=12-$ 14). ${ }^{31}$ Perceived general quality of life was assessed by asking the participants to rate their quality of life, adapted from WHO's quality of life assessment tool. ${ }^{32}$ Relative wealth of the participants was assessed by asking what they perceived about their wealth in relation to others in their neighbourhood. ${ }^{33}$ Problematic alcohol use was assessed by Alcohol Use Disorder Identification Test-Consumption (AUDIT-C) which is a three-item scale with $72 \%$ specificity and $86 \%$ sensitivity for men, and $94 \%$ specificity and $66 \%$ sensitivity for women. ${ }^{34} 35$

\section{Analysis}

Data entry was done with Epi Info V.7 and analysis was done with SPSS V.21. Chi-squared test was used to compare simple frequencies in between groups. We ran univariate logistic regression for each variable to select variables $(p<0.2)$ for the final model. ${ }^{36}$ Multivariable logistic regression analysis was done to identify the associated variables. The strength of associations was indicated by OR with a $95 \%$ CI. Variables with $p$ values $<0.05$ were considered as statistically significant. 
Table 1 Sociodemographic characteristics of the respondents $(N=1026)$

\begin{tabular}{|c|c|c|c|c|c|}
\hline \multirow[b]{2}{*}{ Variables } & & \multicolumn{2}{|l|}{ Sample type } & \multirow[b]{2}{*}{$\begin{array}{l}\text { Overall } \\
\text { N (\%) }\end{array}$} & \multirow[b]{2}{*}{ P value $\left(\chi^{2}\right)$} \\
\hline & & $\begin{array}{l}\text { Community sample } n \\
(\%)\end{array}$ & $\begin{array}{l}\text { ART clinic } \\
\text { sample n (\%) }\end{array}$ & & \\
\hline Sex & Female & $240(48.4)$ & $370(69.8)$ & $610(59.5)$ & \\
\hline Age & $<25$ years & $109(22)$ & $22(4.1)$ & $131(12.8)$ & $<0.001$ \\
\hline \multirow[t]{3}{*}{ Family size } & One (alone) & $100(20.2)$ & $124(23.4)$ & $224(21.8)$ & 0.29 \\
\hline & Two to five & $352(70.9)$ & $369(69.6)$ & $721(70.3)$ & \\
\hline & More than five & $44(8.9)$ & $37(7)$ & $81(7.9)$ & \\
\hline $\begin{array}{l}\text { Family income } \\
\text { compared with } \\
\text { others }\end{array}$ & Better & $20(4)$ & $13(2.5)$ & $33(3.2)$ & $<0.001$ \\
\hline \multirow{3}{*}{ Marital status } & Single & 155 (31.3) & $47(8.9)$ & $202(19.7)$ & \\
\hline & Divorced & $47(9.5)$ & $188(35.5)$ & $235(22.9)$ & \\
\hline & Widowed & $18(3.6)$ & $60(11.3)$ & $78(7.6)$ & \\
\hline \multirow[t]{5}{*}{ Education } & Unable to read and write & $138(27.8)$ & $165(31.1)$ & $303(29.5)$ & 0.2 \\
\hline & Informal education & $61(12.3)$ & 79 (14.9) & $140(13.6)$ & \\
\hline & Elementary school & $99(20)$ & $103(19.4)$ & $202(19.7)$ & \\
\hline & Secondary school & $126(25.4)$ & $106(20)$ & $232(22.6)$ & \\
\hline & College and above & $72(14.5)$ & $77(14.5)$ & $149(14.5)$ & \\
\hline
\end{tabular}

ART, antiretroviral therapy.

\section{RESULTS}

\section{Socio-demographic characteristics of the participants}

From the total of 1115 participants, 1026 (496 from the general population and 530 from the ART clinics) agreed to participate in the study. The reasons for non-response were lack of time to complete the interview $(n=47)$, no interest to participate $(n=23)$ and withdrew from the interview without giving reason $(n=19)$. The mean age of participants was 38.85 years $(\mathrm{SD} \pm 10.72)$ and most of them were in the age group of 25-44 years. The overall divorce and widow rates were $22.9 \%$ and $7.6 \%$, respectively. This is significantly higher in the HIV-positive sample $(35.5 \%$ and $11.3 \%)$ as compared with the community sample $(9.5 \%$ and $3.6 \%), \mathrm{p}<0.001$ (table 1$)$.

\section{Psychosocial and related characteristics}

Khat (Catha edulis, evergreen, psychoactive leaf which is commonly cultivated in East Africa) was chewed by $6 \%$ of participants $(9.5 \%$ in the community sample and $2.8 \%$ in the HIV sample); $\mathrm{p}<0.001$. The HIV-positive participants reported relatively good social support as compared with the community participants (table 2 ).
HIV and other related characteristics of HIV-positive participants

The median duration since HIV status determined was 84 months (IQR 60 months) with a minimum of 2 months and a maximum of 159 months. The median duration since ART started was 60 months (IQR 60 months) with a minimum of 1 month and a maximum of 144 months. The commonly prescribed ART regimens were 1e and 1c, and opportunistic infections in the last 1 month prior to the data collection time were reported by $12(2.3 \%)$ of participants (table 3 ).

\section{Prevalence and associated factors of depressive symptoms}

The overall prevalence of depressive symptoms was $13.3 \%(11.2 \%-15.4 \%)$. The prevalence was significantly higher in people with HIV/AIDS, $16.6 \%(13.4 \%-19.8 \%)$ as compared with the community sample, $9.7 \%(7.1 \%-$ $12.3 \%), p=0.001$. Variables significantly associated with depressive symptoms were older age (adjusted OR (AOR) 2.3, 95\% CI 1.1 to 5.1), HIV-positive sample (AOR 1.7, $95 \%$ CI 1.1 to 2.6 ), being single (AOR $1.9,95 \%$ CI 1.1 to 3.5 ), divorced/widowed (AOR $2.3,95 \%$ CI 1.5 to 3.5 ) and poor social support (AOR $3.9,95 \%$ CI 1.7 to 9.8 ) (table 4 ). 
Table 2 Psychosocial factors of the participants $(\mathrm{N}=1026)$

\begin{tabular}{|c|c|c|c|c|c|}
\hline \multirow[b]{2}{*}{ Variables } & & \multicolumn{2}{|l|}{ Sample type } & \multirow[b]{2}{*}{$\begin{array}{l}\text { Overall } \\
\mathrm{N}(\%)\end{array}$} & \multirow[b]{2}{*}{ P value $\left(\chi^{2}\right)$} \\
\hline & & $\begin{array}{l}\text { Community sample } n \\
(\%)\end{array}$ & $\begin{array}{l}\text { ART clinic } \\
\text { sample } \mathrm{n}(\%)\end{array}$ & & \\
\hline \multirow[t]{2}{*}{ Khat chewing } & Never & 449 (90.5) & $515(97.2)$ & 964 (94) & $<0.001$ \\
\hline & Yes & $47(9.5)$ & $15(2.8)$ & $62(6)$ & \\
\hline \multirow{2}{*}{$\begin{array}{l}\text { Problematic } \\
\text { alcohol use }\end{array}$} & No & $427(86.1)$ & $501(94.5)$ & $928(90.4)$ & $<0.001$ \\
\hline & Yes & $69(13.9)$ & $29(5.5)$ & $98(9.6)$ & \\
\hline \multirow[t]{3}{*}{ Social support } & Poor support & 259 (52.2) & $215(40.6)$ & $474(46.2)$ & $<0.001$ \\
\hline & Intermediate support & $201(40.5)$ & $246(46.4)$ & 447 (43.6) & \\
\hline & Strong support & $36(7.3)$ & $69(13)$ & $105(10.2)$ & \\
\hline \multirow{4}{*}{$\begin{array}{l}\text { Depressive } \\
\text { symptoms }\end{array}$} & None/mild & $448(90.3)$ & $442(83.4)$ & $890(86.7)$ & 0.001 \\
\hline & Moderate & $23(4.6)$ & $62(11.7)$ & $85(8.3)$ & \\
\hline & Moderately severe & $21(4.2)$ & $24(4.5)$ & $45(4.4)$ & \\
\hline & Severe & $4(0.8)$ & $2(0.4)$ & $6(0.6)$ & \\
\hline
\end{tabular}

ART, antiretroviral therapy.

\section{DISCUSSION}

This study reported that the prevalence of moderate to severe depressive symptoms is significantly higher in HIV-positive participants (16.6\%) compared with the general population sample $(9.7 \%)$. This variation was also indicated in the multivariable logistic regression analysis where the odds of depressive symptoms in people with HIV/AIDS was 1.7 times higher than the community sample. The additional burdens in HIV-positive participants including opportunistic infections, ART drug side effects and lower level of CD4 count $(54.5 \%$ of HIV-positive participants have less than $500 \mathrm{CD} 4$ ) may contribute to this increased prevalence of depressive symptoms in the HIV-positive sample. The finding is in line with the Chinese study $(18.33 \%),{ }^{37}$ higher than Ugandan $(8.1 \%)$ and US $(12.2 \%)^{38} 39$ studies, and lower than the Cameroon study (26.7\%) and other sub-Saharan countries $(26 \%-28 \%){ }^{40-42}$

Multiple conditions including HIV-related stigma, ${ }^{43-45}$ poor adherence to antiretroviral therapy ${ }^{46-48}$ and the direct effect of the virus ${ }^{49}$ are possible reasons for the excess odds of depressive symptoms in HIV-positive individuals. New perspectives towards non-medical services and resource allocation, ${ }^{50}$ and interventions focusing on reduction of risk behaviour and social stigma would decrease the prevalence of depressive symptoms in HIVpositive individuals. ${ }^{51}$ The advancements in HIV prevention and treatment are becoming promising in ending

Table 3 HIV-related factors of the ART clinic participants $(n=530)$

\begin{tabular}{|c|c|c|c|c|}
\hline \multirow{2}{*}{ Variables } & & \multicolumn{2}{|c|}{ Depressive symptoms } & \multirow[b]{2}{*}{ P value $\left(\chi^{2}\right)$} \\
\hline & & No n (\%) & Yes n (\%) & \\
\hline \multirow{2}{*}{ Duration since knowing HIV status } & Less than 5 years & $132(24.9)$ & $19(3.6)$ & 0.1 \\
\hline & 5 years and above & $310(58.5)$ & $69(13)$ & \\
\hline \multirow[t]{2}{*}{ Duration of ART } & Less than 5 years & $191(36)$ & $33(6.2)$ & 0.3 \\
\hline & 5 years and above & $251(47.4)$ & $55(10.4)$ & \\
\hline \multirow[t]{4}{*}{ ART drug regimen } & $1 \mathrm{c}$ & $166(31.3)$ & $35(6.6)$ & 0.8 \\
\hline & $1 d$ & $54(10.2)$ & $13(2.4)$ & \\
\hline & $1 e$ & $197(37.2)$ & $36(6.8)$ & \\
\hline & $1 f$ & $25(4.7)$ & $4(0.8)$ & \\
\hline \multirow[t]{2}{*}{ Opportunistic infections } & Yes & $4(0.8)$ & $8(1.5)$ & $<0.001$ \\
\hline & No & $438(82.6)$ & $80(15.1)$ & \\
\hline \multirow[t]{2}{*}{ CD4 level } & Less than 500 & $228(43)$ & $61(11.5)$ & 0.002 \\
\hline & 500 and above & $214(40.4)$ & $27(5.1)$ & \\
\hline
\end{tabular}

1c=zidovudine (AZT)+lamivudine (3TC)+nevirapine (NVP); 1d=AZT+3TC+efavirenz (EFV); 1e=tenofovir (TDF)+3TC+EFV; 1f=TDF+3TC+NVP. ART, antiretroviral therapy. 
Table 4 Factors associated with depressive symptoms $(\mathrm{N}=1026)$

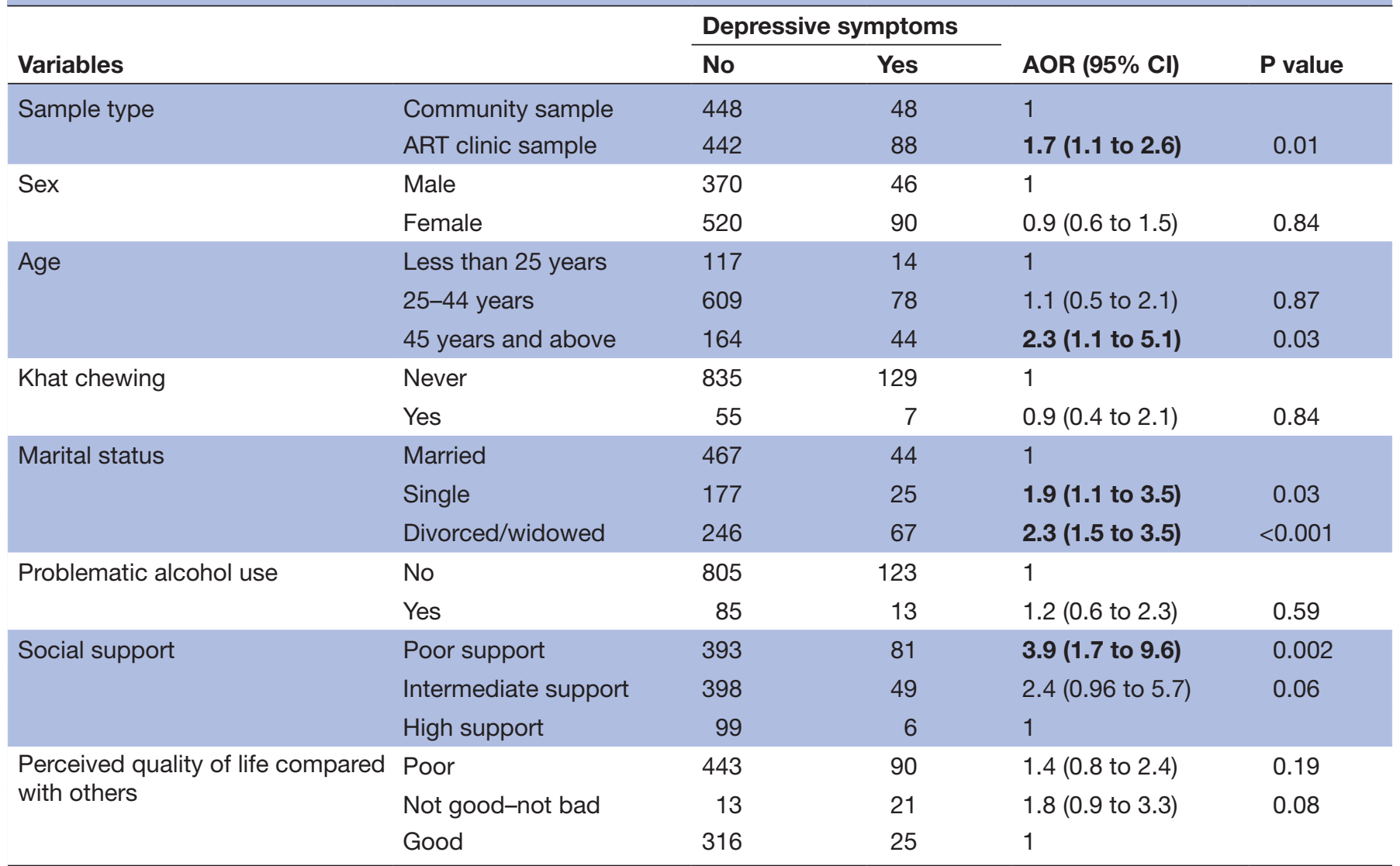

Bold values indicate statistically significant association.

AOR, adjusted OR; ART, antiretroviral therapy.

the HIV epidemic. However, this might be difficult to achieve without addressing depression and other mental health issues in HIV/AIDS care.

Marital status, age and social support were important factors associated with depressive symptoms in the overall sample of this study. The odds of depressive symptoms in single and divorced/widowed participants was nearly twofold as compared with their married counterparts. Marital tragedies are the most stressful events ${ }^{52}$ that can lead to a sense of insecurity and hopelessness. The odds of having depressive symptoms at the age of 45 years and above was more than twofold as compared with those with younger age (25 years and below). Poor social support is also strongly and positively associated with depressive symptoms in which participants with poor social support were about four times more likely to have depressive symptoms compared with participants with high social support. Social interaction between family members and the family's ability to react positively to life changes are important to reassuring individuals and maintaining social cohesion. ${ }^{53}$ On the other hand, if this social connectedness gets loose, the individual might feel lonely and depressed. This finding is supported by the study in Ethiopia and other sub-Saharan countries. ${ }^{4154}$

In general, this study provided evidence about depressive symptoms in patients with HIV/AIDS by comparing it with the general population. In the current study, gender, perceived quality of life compared with others, and substance use (khat chewing and alcohol do not involve intravenous administration) were not statistically significant. However, recent finding indicates HIV-positive individuals with drug injection were more likely to have depression. $^{55}$

\section{Limitations}

The study has some limitations to take into consideration in interpretations of the result. The first limitation is with matching. It would have been better if we did a matching of important variables for depression such as sex and age in both groups. The other potential limitation is that we did not conduct HIV testing in the general population comparison group to exclude those with positive HIV test results. Although we excluded those who reported their HIV-positive status in the comparison group, we were not able to exclude those who are HIV positive but who did not know their status.

\section{CONCLUSIONS}

Depressive symptoms are significantly higher in people with HIV/AIDS compared with the general population. The higher prevalence of depressive symptoms in people 
with HIV/AIDS is an important public health issue that urges the incorporation of mental healthcare and depression screening in routine HIV/AIDS care.

Acknowledgements We are very thankful to the study participants for their volunteer participation and Bahir Dar University for the financial support.

Contributors All authors (TM, HB and WF) equally contributed from the conception to the completion of this project.

Funding This research was supported by Bahir Dar University via Mecha Demographic Surveillance and Field Research Centre, grant number (not applicable).

\section{Competing interests None declared.}

Patient and public involvement Patients and/or the public were not involved in the design, or conduct, or reporting, or dissemination plans of this research.

\section{Patient consent for publication Not required.}

Ethics approval Ethical clearance was obtained from the College of Medicine and Health Sciences ethical review committee of Bahir Dar University. Formal permission letter was obtained from the University and local administration. Participants were informed about the purpose of the study, confidentiality and their rights to withdraw from the interview at any time they want. Informed consent was obtained from each participant. To maintain confidentiality, the questionnaire was anonymous, and the data were kept in a secure place.

Provenance and peer review Not commissioned; externally peer reviewed.

Data availability statement The data related to this research will be available on reasonable request.

Open access This is an open access article distributed in accordance with the Creative Commons Attribution Non Commercial (CC BY-NC 4.0) license, which permits others to distribute, remix, adapt, build upon this work non-commercially, and license their derivative works on different terms, provided the original work is properly cited, appropriate credit is given, any changes made indicated, and the use is non-commercial. See: http://creativecommons.org/licenses/by-nc/4.0/.

\section{ORCID iDs}

Tesfa Mekonen http://orcid.org/0000-0002-3188-0173

Habte Belete http://orcid.org/0000-0003-0208-9144

Wubalem Fekadu http://orcid.org/0000-0001-7418-4955

\section{REFERENCES}

1 GBD 2017 HIV collaborators. Global, regional, and national incidence, prevalence, and mortality of HIV, 1980-2017, and forecasts to 2030, for 195 countries and territories: a systematic analysis for the global burden of diseases, injuries, and risk factors study 2017. Lancet HIV 2019;6:e831-59.

2 UNAIDS. Global HIV \& AIDS statistics - 2020 fact sheet, 2020.

3 Kang H-J, Kim S-Y, Bae K-Y, et al. Comorbidity of depression with physical disorders: research and clinical implications. Chonnam Med J 2015;51:8-18.

4 World Health Organization. Depression: a global crisis. world mental health day. Occoquan, VA, USA: World Federation for Mental Health, 2012.

5 Ciesla JA, Roberts JE. Meta-analysis of the relationship between HIV infection and risk for depressive disorders. Am J Psychiatry 2001;158:725-30.

6 Jin H, Hampton Atkinson J, Yu X, et al. Depression and suicidality in HIV/AIDS in China. J Affect Disord 2006;94:269-75.

7 Rabkin JG. HIV and depression: 2008 review and update. Curr HIVI AIDS Rep 2008;5:163-71.

8 Nakasujja N, Skolasky RL, Musisi S, et al. Depression symptoms and cognitive function among individuals with advanced HIV infection initiating HAART in Uganda. BMC Psychiatry 2010;10:44.

9 Nakimuli-Mpungu E, Bass JK, Alexandre P, et al. Depression, alcohol use and adherence to antiretroviral therapy in sub-Saharan Africa: a systematic review. AIDS Behav 2012;16:2101-18.

10 Rezaei S, Ahmadi S, Rahmati J, et al. Global prevalence of depression in HIV/AIDS: a systematic review and meta-analysis. BMJ Support Palliat Care 2019;9:404-12.

11 Eshun-Wilson I, Akena DH, Siegfried N, et al. Antidepressants for depression in adults with HIV infection. 7. John Wiley \& Sons, Ltd: Cochrane Database of Systematic Reviews, 2014.
12 Leserman J. Role of depression, stress, and trauma in HIV disease progression. Psychosom Med 2008;70:539-45.

13 Wagner GJ, Ghosh-Dastidar B, Dickens A, et al. Depression and its relationship to work status and income among HIV clients in Uganda World J AIDS 2012;2:126-34.

14 Amberbir A, Woldemichael K, Getachew S, et al. Predictors of adherence to antiretroviral therapy among HIV-infected persons: a prospective study in Southwest Ethiopia. BMC Public Health 2008;8:265.

15 Bhatia MS, Munjal S. Prevalence of depression in people living with HIV/AIDS undergoing art and factors associated with it. J Clin Diagn Res 2014;8:WC01-4.

16 Hailemariam S, Tessema F, Asefa M, et al. The prevalence of depression and associated factors in Ethiopia: findings from the national health survey. Int J Ment Health Syst 2012;6:23.

17 Kamen C, Arganbright J, Kienitz E, et al. HIV-related stigma: implications for symptoms of anxiety and depression among Malawian women. Afr J AIDS Res 2015;14:67-73.

18 Oladeji BD, Taiwo B, Mosuro O, et al. Suicidal behavior and associations with quality of life among HIV-infected patients in Ibadan, Nigeria. J Int Assoc Provid AIDS Care 2017;16:376-82.

19 Tran B, Dang A, Truong N, et al. Depression and quality of life among patients living with HIV/AIDS in the era of universal treatment access in Vietnam. Int J Environ Res Public Health 2018;15:2888.

20 Chibanda D, Cowan F, Gibson L, et al. Prevalence and correlates of probable common mental disorders in a population with high prevalence of HIV in Zimbabwe. BMC Psychiatry 2016;16:55.

21 Asch SM, Kilbourne AM, Gifford AL, et al. Underdiagnosis of depression in HIV: who are we missing? J Gen Intern Med 2003;18:450-60.

22 Andersen L, Kagee A, O'Cleirigh C, et al. Understanding the experience and manifestation of depression in people living with HIV/ AIDS in South Africa. AIDS Care 2015;27:59-62.

23 Collins PY, Holman AR, Freeman MC, et al. What is the relevance of mental health to HIV/AIDS care and treatment programs in developing countries? A systematic review. AIDS 2006;20:1571-82.

24 Odokonyero R, Wagner G, Ngo V, et al. Giving "sadness" a name: the need for integrating depression treatment into HIV care in Uganda. $J$ Int Assoc Provid AIDS Care 2015;14:108-11.

25 Beyene Gebrezgiabher B, Huluf Abraha T, Hailu E, et al. Depression among adult HIV/AIDS patients attending ART clinics at Aksum town, Aksum, Ethiopia: a cross-sectional study. Depress Res Treat 2019;2019:1-8.

26 Abadiga M. Depression and its associated factors among HIV/ AIDS patients attending art clinics at Gimbi General Hospital, West Ethiopia, 2018. BMC Res Notes 2019;12:527.

27 Duko B, Geja E, Zewude M, et al. Prevalence and associated factors of depression among patients with HIV/AIDS in Hawassa, Ethiopia, cross-sectional study. Ann Gen Psychiatry 2018;17:45.

28 Mekuria LA, Sprangers MAG, Prins JM, et al. Health-related quality of life of HIV-infected adults receiving combination antiretroviral therapy in Addis Ababa. AIDS Care 2015;27:934-45.

29 Gelaye B, Williams MA, Lemma S, et al. Validity of the Patient Health Questionnaire-9 for depression screening and diagnosis in East Africa. Psychiatry Res 2013;210:653-61.

30 Kroenke K, Spitzer RL, Williams JBW. The PHQ-9. J Gen Intern Med 2001;16:606-13.

31 Abiola T, Udofia O, Zakari M. Psychometric properties of the 3-item Oslo Social Support Scale among clinical students of Bayero University Kano, Nigeria. Malaysian Journal of Psychiatry 2013;22:32-41.

32 Murphy B, Herrman H, Hawthorne G. Australian WHOQoL instruments: user's manual and interpretation guide. Melbourne, Australia: Australian WHOQOL Field Study Centre, 2000.

33 Fekadu A, Medhin G, Selamu M, et al. Population level mental distress in rural Ethiopia. BMC Psychiatry 2014;14:194.

34 Bradley KA, Bush KR, Epler AJ, et al. Two brief alcohol-screening tests from the Alcohol Use Disorders Identification Test (AUDIT): validation in a female Veterans Affairs patient population. Arch Intern Med 2003;163:821-9.

35 Bush K, Kivlahan DR, McDonell MB, et al. The audit alcohol consumption questions (AUDIT-C): an effective brief screening test for problem drinking. ambulatory care quality improvement project (ACQUIP). alcohol use disorders identification test. Arch Intern Med 1998;158:1789-95.

36 Sperandei S. Understanding logistic regression analysis. Biochem Med 2014;24:12-18.

37 Jiang $\mathrm{Y}$, Wang $\mathrm{M}$, Wei $\mathrm{XQ}$, et al. [Prevalence of depression and related factors in 180 HIV/AIDS patients receiving highly active antiretroviral therapy]. Zhonghua Liu Xing Bing Xue Za Zhi 2016;37:638-42. 
38 Kinyanda E, Hoskins S, Nakku J, et al. Prevalence and risk factors of major depressive disorder in HIV/AIDS as seen in semi-urban Entebbe district, Uganda. BMC Psychiatry 2011;11:205.

39 Skalski LM, Watt MH, MacFarlane JC, et al. Mental health and substance use among patients in a North Carolina HIV clinic. N C Med J 2015;76:148-55.

40 Ngum PA, Fon PN, Ngu RC, et al. Depression among HIV/AIDS patients on highly active antiretroviral therapy in the southwest regional hospitals of Cameroon: a cross-sectional study. Neurol Ther 2017:6:103-14.

41 Seth P, Kidder D, Pals S, et al. Psychosocial functioning and depressive symptoms among HIV-positive persons receiving care and treatment in Kenya, Namibia, and Tanzania. Prev Sci 2014;15:318-28.

42 Olley BO, Seedat S, Stein DJ. Persistence of psychiatric disorders in a cohort of HIV/AIDS patients in South Africa: a 6-month follow-up study. J Psychosom Res 2006;61:479-84.

43 Endeshaw M, Walson J, Rawlins S, et al. Stigma in Ethiopia: association with depressive symptoms in people with HIV. AIDS Care 2014;26:935-9.

44 Nachega JB, Morroni C, Zuniga JM, et al. HIV-related stigma, isolation, discrimination, and serostatus disclosure: a global survey of 2035 HIV-infected adults. J Int Assoc Physicians AIDS Care 2012;11:172-8.

45 Onyebuchi-Iwudibia O, Brown A. HIV and depression in eastern Nigeria: the role of HIV-related stigma. AIDS Care 2014;26:653-7.

46 Malow R, Dévieux JG, Stein JA, et al. Depression, substance abuse and other contextual predictors of adherence to antiretroviral therapy (ART) among Haitians. AIDS Behav 2013;17:1221-30.
47 Sin NL, DiMatteo MR. Depression treatment enhances adherence to antiretroviral therapy: a meta-analysis. Ann Behav Med 2014;47:259-69.

48 Wroe EB, Hedt-Gauthier BL, Franke MF, et al. Depression and patterns of self-reported adherence to antiretroviral therapy in Rwanda. Int J STD AIDS 2015;26:257-61.

49 Del Guerra FB, Fonseca JLI, Figueiredo VM, et al. Human immunodeficiency virus-associated depression: contributions of immuno-inflammatory, monoaminergic, neurodegenerative, and neurotrophic pathways. J Neurovirol 2013;19:314-27.

50 Tran BX, Do HP, Hall B, et al. The use of health behavioral theories in HIV/AIDS research: a bibliometric analysis (GAP research). AIDS ReV 2019;21:93-107.

51 Tran BX, Ho RCM, Ho CSH, et al. Depression among patients with HIV/AIDS: research development and effective interventions (GAPRESEARCH). Int J Environ Res Public Health 2019;16:1772.

52 Holmes $\mathrm{TH}$, Rahe $\mathrm{RH}$. The social readjustment rating scale. $J$ Psychosom Res 1967;11:213-8.

53 Wouters E, Masquillier C, le Roux Booysen F. The importance of the family: a longitudinal study of the predictors of depression in HIV patients in South Africa. AIDS Behav 2016;20:1591-602.

54 Tesfaw G, Ayano G, Awoke T, et al. Prevalence and correlates of depression and anxiety among patients with HIV on-follow up at alert Hospital, Addis Ababa, Ethiopia. BMC Psychiatry 2016;16:368.

55 Than PQT, Tran BX, Nguyen CT, et al. Stigma against patients with HIV/AIDS in the rapid expansion of antiretroviral treatment in large drug injection-driven HIV epidemics of Vietnam. Harm Reduct $J$ 2019;16:6. 